\title{
TUMBLR: Homogeneity and heterogeneity, production and reproduction of expenditure
}

\section{TUMBLR: Homogeneidade e heterogeneidade - produção e reprodução de despesa}

Pedro Henrique Baptista Reis

Doutor em Comunicação pela Pontifícia Universidade Católica do Rio Grande do Sul $<$ pedro.reis.hb@gmail.com>

\section{ABSTRACT}

This paper endeavours in comprehending the processes of production and reproduction of content in the social networking site Tumblr under the guise of Battaile's theory of expenditure and the aspects of homogeneity and heterogeneity in post-totalitarian societies. The main focus is the analysis of blogs connected trough the social networking site Tumblr, in a diverse rage of categories, from the amateuristic production of content to the reproduction of culture media products, but always concern with the transgressor nature of the apropriation of pornographic and/or erotic ideas.

\section{RESUMO}

Este trabalho objetiva compreender os processos de produção e reprodução de conteúdo na rede social Tumblr sob o prisma da teoria batailleana da despesa e dos aspectos de homogeneidade e heterogeneidade na formação de sociedades pós-totalitárias. O foco principal é a análise de blogs em diversas categorias, desde produção amadorística de conteúdo até a reprodução de conteúdos da cultura mídia, mas centrados nas ideias transgressoras de apropriação de conteúdos pornográficos e/ou eróticos.

Palavras-chave: Cibercultura. Redes Sociais. Pornografia.

Keywords: Cyberculture. Social Neworking. Pornography.

The inability of homogeneous society to find in itself a reason for being and acting is what makes it dependent upon imperative forces.

Georges Bataille

In the current state of rapid proliferation of online social networks and online social media, with its most popular examples being Facebook and Twitter, we've come to find a tool that emerges as a linkage between old, now classic formats of internet media proliferation and social interaction and these new modes. Tumblr was founded in 2007 by David Karp and Marco Arment and consists in a mashed-up version of a common old-fashioned blog, like those hosted by wordpress.com ou blogspot.com. and the functionalities of more 
current forms of online social networking such as Facebook and Twitter. Blogs (which can be created via templates offered for free or paid ones) where users can post photos, texts, quotes, links, vídeos and many more formats of digital content are presented and followed or friended in much the same way you follow a Twitter profile or friends a Facebook user. This allows users to construct networks based on content and presented as a timeline or infinite dashboard ${ }^{1}$ composed of feeds from the posting activities of other users on their respective blogs. Posts usually have tags that gather similar content or topics together, allowing the user to search not only a specific theme, subject or person, but a chained network of content-sharing users approaching a specific theme or subject. In other words, Linking or reblogging ${ }^{2}$ a certain post, be it text, photo, video or link, carries with it the tag conferred to the original post (of course this can be disabled, but very rarely is): a kind of narrative of any particular post. Users can add to the original post (either videos, other photos, comments, etc.) and by that they link the story, availability and visibility of the post creating a sort of chained narrative.

Tumblr also differs from other social networks for being open in a sense that could be described as organized informational chaos. With hundreds of thousands of blogs (many belonging to the same user or users) it presents almost unintelligible contents (for the initiate and for the layman, so to speak) and blog designs with a especially high frequency of posts and post/answer ratio that rivals on everyday use the rate of tweets around a certain worldwide event. All this takes place at a completely censorship-free environment. No content, be it photographic, filmographic or textual is subject to any kind of previous or posterior censorship. The claims for removal of certain posts are exclusively made by other users and are rarely answered by the staff/administrators of Tumblr.

Thus, our objective here is to articulate the notions of homogeneous society and expenditure, as worked by Georges Battaile in two specific texts: "The Psychological Structure of Fascism" (1979) and "The Notion of Expenditure" (1997). The basis for such an articulation involved in the production and

$1 \quad$ On Facebook, for examples, the user has a Wall or Timeline. Posts made by other users and pages appear chronologically or in a order of importance decided by an algorithm that recognizes your interests. On the microblog social network Twitter, much like Facebook, posts made by profiles followed by said user appear chronologically (earlier to older). On Tumblr this system is the same, earlier posts to older posts, and the user can scroll down seemingly forever, browsing through posts made by blogs that are followed or sponsored by Tumblr itself.

2 Tumblr's version of Twitter's retweet, but much more central to the whole of the interface and activity on this social media platform. 
reproduction of free contents provided by the censor-free digital environment of Tumblr will be the notions of power (as modulated between power, strength and vigor), authority and physical and moral violence as interpreted by Hannah Arend, mainly on the books "On Violence" (2010) and "On Revolution" (2001). We justify such provisory analytical articulations as studies not only on the fields of communication, media criticism and, more specifically, in the field of cyberculture and internet studies, but as preliminary thoughts on freedom of speech and of cultural production and reproduction in the scope of the phenomenon marked by Bataille as expenditure - this reserved generated by all human action and thought.

\section{TUMBLR - a two-time-bomb}

From 2007 to 2011, Tumblr went from having a little over 75 thousand users to more than 3 million and, on an early 2010 memo issued by the creators of the site, they confirm that the site gains about 15 thousand users (with retention numbers being as high as to $80 \%{ }^{3}$ ). It has more than 2 million confirmed individual posts per day. This almost verborragic torrent of informations needs to be first and foremost perceived as the main and most important facet of the functionality of the site: the reblog feature. Much like Twitter, this feature allows users to replicate or repost any and all content made public on blogs (either followed or unfollowed blogs). This rapidly generated and still generates content appropriation strategies of all kinds of formats and a chained appropriation strategy where reblogs become not only re-affirmations of content (textual or otherwise) but also reinforcements of ideas shared through theses posts as well as ask/response reworkings of such contents. These chains can be reconstructed through the notes - every time a user or blog reblogs or likes a post or content the original and reblogged content presents the number of activities related to that said post or content as well as the username or blog name related to the activity. I.e: if user $x$ likes a photo posted on user $y$ 's blog the photo or text page (or permalink page, as it is named on Tumblr) of the post will show the number of likes/reblogs as well as the username/blog that liked and/or reblogged that photo. This way the notes serve as traces or trails - or, even better, footsteps - that allowed us to reconstruct the chains of relationships and content production and reproduction - the chained narrative.

$3 \quad$ These numbers are confirmed by a survey conducted by the website fastcompany.com and made available on a piece publish in late 2009 and available at http://www.fastcompany.com/blog/ chris-dannen/techwatch/what-hell-tumblr-and-other-worthwhile-questions (accessed on July 14th, 2011). 
These footsteps are evidence of a diverse number of specific cultural aspects: reappropriation of media texts, political and social contestation, biographical narratives (some blogs are still engaged in the more traditional use of the personal internet blog, of being a sort of open journal where people narrate their lives, inner thoughts, and emotions) and a whole other myriad of authored content and authorship problems (such as piracy and undue appropriation of copyrighted materials, etc.). However, for our purposes here, two matters are made essential: first, the appropriation of what we'd like to call the underbelly of the cultural industry, such as films and other visual contents of pornographic or erotic nature usually distributed through alternative media outlets (such as on-demand content purchased on the internet, be it either fully digital or physical) and usually largely ignored by research and common media market analysis and investment. And, secondly, the aspect of (re)production of said contents in articulation with mainstream cultural industry products (usually, but not always) in an amateurish manner or mode.

These normalized relations of re-distribution of contents are characterized by a form of tautism (Sfez, 1994) - a tautological cacophony - but are at the same time subject to reformulations not especially accentuated by narrative modes, such as the case of Schn., where a narrative is never remade or retold "as it was first told to the person", where the nacherzählen appears without any accent (or it's direct reverse: the characterization or formation of identity indexes appear without accent beyond what the original narrative advocates) and without any form of comprehension of the "progression of the story" (Mearley-Ponty, 2006, p.186).

Here are the two fundamental points of our investigation: the notion of authority as seen through the prism of cultural and identifying re-appropriations and the dialectics homogeneity/heterogeneity as participants in the construction of social relations and as co and re-creators of content. Authority can be an illusive notion, often referring to the common mistake of imagining it as an autochthonous phenomenon or group of phenomena, as a phantasmatic presence under and over all institutions and individual personalities. This is far from true. Authority is "invested in people [...], or can be invested in professions [...]; or even in hierarchical positions" (Arendt, 2010, p.62): power is something conferred by individuals and groups of individuals and authority is a projection phenomenon: "its banner is the unquestionable recognition from those that are asked to obey" (Idem).

By appropriating this understanding of authority, we can adapt it to better appreciate the set of phenomena covered (partly, of course) by this 
essay. We can, then, realize that the relationships involved have less to do with obedience and more with identifying oneself as a follower and acting on these identifications through specific strategies - namely the reblogging feature. Cultural icons - such as bands, actors and actress, films and book series - appear throughout the analyzed cases we present here as institutionalized and supraindividual. In them, individual and networks of individuals find validation of a certain form of authority that echoes the natural laws or the superhuman/ theological mandates where "the criteria of right and wrong [...] as necessarily general and valid to every and all cases, either predictable or not" (Arendt, 1989, p.514) - case in point: each specific blog, each specific post in each specific blog and the specificity of the social network in itself must obey these abstract set of rules that are continually reworked and redefined.

This makes way for us to recognize that the attitudes of creation and re-creation of contents are externalized as hiper-identities and are essentially confrontational, they appear as (re)affirmations that work in order to reinforce homogeneity or heterogeneity: bonds are built, voluntary associations to many kinds of different contents (from rock bands to gay rights movements and more) are perpetrated through the reproduction of available contents and are made in contrast to other contents that are deemed oppositional or contrary. There isn't necessarily interaction, but iteration. A tautism in circuit that builds a network between users and contents: a user reblogs a certain content, but the endgame of this action is not a relation with the original creator of that content, but is, instead, a relation of the user to a certain content and what it represents to him/ her.

In this reproduction strategy footsteps are left behind and those serve as the clues we intend to follow as to define the group of blogs we want to analyse. They serve us not only in forming the snippet we must use in order not to face such a great scope of blogs; they also reveal the dualistic logic between homogeneity and heterogeneity as identifying factors - or, in other words, that in which oneself refers to oneself - taste, consumption, compulsions can already be marked "as something other" (Bataille, 1979, p.70) that brings those selves together in a non-functional ou pragmatical way. There's no search for an inherent meaning in this: as the example put forward by Bataille (Idem.): lord and slave that are put on diametrically opposite sides of a sense of purity. The complete pureness of the lord expressed in its own heterogeneity is what allows for an overview of the homogeneity or homogenizing processes existing in said community or society. Reversing that, we can think of online social networks and much of the whole of socially active parts of the Internet as spaces of reversibility 
of said homogeneity: they can be seem as spaces (never forgetting they are not, naturally nor literally, physical spaces but shared electronic non-places) of expenditure - as space-time aberrations that allow individuals to not only live and enjoy but to create and augment excesses that are, in their cores, essentially non-homogenizing because they are the leftovers of contrasts. In previous spaces (or even non-places) such as these, "humanity recognizes its right to rationally adquire, converse and consume, but the productive expenditure is excluded" (Bataille, 1997, p.117). Here the consumption of cultural products reveals itself as also containing this productive expenditure.

And it appears, we'd argue, in energetic explosions. Blogs such as Stay Beautiful and Keep It Ugly ${ }^{4}$ construct narratives through images, texts and videos (most of those reblogged content from other blogs) about personal difficulties and problems of the user - in this particular case, the user is a twentysomething girl that has undergone many psychological and medical treatments due to eating disorders. The narrative and self-help/help-hotline aspects of the blog make it a stage for identification and identification processes of other users with the life struggles faced by the curator-creator-user as well as a sort of escape valve that attests to public health concerns as much as a sort of "you are not alone" claim for others going through the same issues. These become evident when following the footsteps of the notes: we find other very similar blogs engaged in conversation via reblogs and reworkings of content made available by the user. The narratives exposed through the blog are constructed via direct relation to popular cultural in general - drawing from celebrities and persons of interests that have also shared online their struggles with eating disorders. It's a process of compilation: not only of the user-owner of Stay Beautiful and Keep it Ugly, but of and from the whole network that is incidentally constructed around her.

In an opposite example, the blog Cue Disappointment ${ }^{5}$ also builds on personal narratives, but never letting it show. It criticizes mass culture (and in a kind of metalanguage, the processes of homogenization of contemporary culture via the icons of popular culture and popular mainstream media). The user constructs what we could call mosaics of estrangement, collages of eschatological, porno-erotic, abuse and violent imagery that criticizes and quips modern contemporary mainstream culture (especially media culture). In much

$4 \quad$ Available at $<$ http://mal-Ifc.tumblr.com/ $>$

5 Available at <http://cuedisappointment.tumblr.com/> 
the same way, the footsteps also lead to other blogs that mimic or emulate Cue Disappointment's style and narrative construction.

While Stay Beautiful and Keep It Ugly presents us with a highly emotional self-help strategy (almost a psychoterapeutic digital experience), Cue Disappointment is a mix of satire and mockery. So, inverse relations, but both connected to the recognition of a sort of authority that must be conjured in order to adhere to the comprehension of the operationalization of these authorities as something lived and felt, either as adherence to it (drawing on it for legitimation) or, as Hannah Arendt puts it better than anyone (2010, p.62), to develop despise for it: "it's greater enemy". In the first blog, the user also utilizes satire to question the criteria of beauty and physical attractiveness and what she deems "depression society", but she still draws from mainstream, let's say, alternatives. In Cue Disappointment what is at stake is not only the many discourses contained in contemporary mass media outlets but the full range of action of these media. Both, even though with very different approaches and even more different objetives, live the double-standing of "sometimes attraction, sometimes repulse, and, in some cases, an object of repulse can become one of attraction and vice-versa" (Bataille, 1979, p.69).

These kinds of relationships between (re)producers of digital content is not limited to the duality between a relational or existential excess. They are also not limited by criticism or adherence to mainstream media discourses. On Tumblr, one of the most prolific networks of blogs/users/content is directly related to pornographic ou erotica content. Excluded from the so-called mainstream - and we could argue, mutatis mutandis, from the "establishment" (Arendt, 2010, p.91) - these blogs, users and types of contents endeavour in making public statements and relational exchanges about the variability and plurality of sexuality in contemporary times. It is pretty well documented, especially by exponents of feminist and queer theory, such as, for example, Judith Butler, that sexuality is usually excluded or normalized by mainstream media imagery and discourses, but it reappears on these micro-networked blogspheres, and mostly through the free-censorship functionality of Tumblr, in the form of a catenation circuit that ranges from simple homemade videos and photographic essays to violent abuse imagery and how-to content explaining practices of BDSM (bondage and discipline, dominance and submission, sadism and masochism).

Sexual fetishism, in many of its more common forms (if we can speak of commonality being that we are arguing that these forms are exactly noncommon forms of online interaction), such as women masturbating man in 
positions of submission or humiliation, appear on blogs such as Milk That Cock, to huge collections of home-made videos and photos that emulate professional porn films, such as Gave me an Erection ${ }^{7}$. Many more forms and types of blogs have been reviewed for the construction of this short essay.

First and foremost, this plentifulness of contents, sharing and producing strategies must be categorized in three different axis: first we need to differentiate specific blogs and networks of blogs inside Tumblr that are directly dedicated to the appropriation and reappropriation of said official contents. This means: those blogs that use as their main strategies the reblogging and reformatting of professional content made available on the Internet by the many (many!) companies and private enterprises dedicated to the production of pornographic and erotic products (films, short-clips, photo shoots, etc.). These companies are usually located on the United States west coast, on a region close to the city of Los Angeles commonly nicknamed Porno Valley, or on the east european post-communist countries (mainly Russia itself and some of it's satellite countries such as Ukraine, Belarus, Georgia, Czech Republic, Slovakia, etc.). A second category would have to be the blogs and networks of blogs that appropriate conventional mass media content, altering said contents through digital tools (such as Adobe's Photoshop and other photo editing applications) or reproducing content made available by mainstream media but recontextualized as erotic or pornographic in someway or another. Finally, the last category is connected to the phenomena of user generated content (UGC), as characterized by author such as Andrew Keen (2008), being composed of blogs and networks of blogs dedicated to making home-made pornographic and erotic content available for free or as a call-to-buy in some other 'outside of Tumblr outlet' (such as MyCamGirl.com or other sites that help individuals to commercialize their video or photographic original content - this would deserve another essay or article).

Right away we can realize that the phenomena are directed by a heterogenization of reality:

"A force or shock. It presents itself as change, as a value, passing from one object to the other in a more or less abstract way, almost as if change had no place in the world of objects but only in the judgement of the subjects" (Bataille, 1979, p.70)".

6 Available at $<$ http://milkthatcock.tumblr.com/>

7 Available at $<$ http://onnerphace.tumblr.com/> 
Blogs like Flesh is Heaven ${ }^{8}$ created routes of re-appropriation of artistic contents mainly connected with imagery of women and womanhood. It does have a take on erotica or pornographic contents and the photos, videos, and gifs $^{9}$ made available are also available in a widespread of other media outlets (either on and offline), usually produced and distributed by the aforementioned content-producing centres in North America and east Europe. The objective here is a sort of marriage or conjugation of these contents in a manner that highlights personal preferences regarding the aesthetics of pornographic or erotic content, creating a form of sexual preference narrative. This blog too forms throughout its footsteps a network of other similar blogs that draw on its contents and also supply it.

In another example, Funny and Sexy ${ }^{10}$, there's no discernible narrativity. The user and/or users are only engaged in re-distributing these same kinds of contents as Flesh is Heaven. The videos, photos, and gifs usually feature well known actors and actress from the world of mainstream porn (such as James Deen, Jenna Jameson and Sasha Grey). The blog reproduces photoshoots, videos and other contents from known outlets of the genre (usually content only available behind some sort of paywall or subscription), such as Playboy, Hustler, MPL Studios, etc. We could call it a purely reblog blog, or a homage blog. It could also be feature in a possible and future article about porn, Tumblr, and the illegal or pirated distribution of content.

A third example is the blog Double Digit Dongle ${ }^{11}$. Here the user and/ or users choose to conjugate both strategies. Images and contents from the mainstream porn industry and mass media are interspersed, creating a narrativity that connects the affirmations of sexuality made very explicit by porn producers and porn culture and the (sometimes not so) implicit claims made by mainstream mass media. There's almost a hint of criticism, as if the blog was being used to make the argument that the language porn industry is not at all that different from the normative and often moralistic media culture language that prevails on common mass media outlets.

However, all three blogs could be seen as being part of a categorization construed by the porn industry itself. What is called softcore. There's nudity, in

$8 \quad$ Available at $<$ http://fleshisheaven.tumblr.com/>

9 GIFs are animated images, frequently edited from larger videos or made through photos and other types of contents (animations, etc). They are named according to their file extensions: i.e, photo. gif.

10 Available at $<\underline{\text { http://funnyandsexy.tumblr.com/ }>}$

11 Available at $<$ http://d-d-d.tumblr.com/> 
certain cases masturbatory and often violent or abusive, but there's no fellatio, no intercourse (either heternormative or not) and no ejaculation (actually, there are very few posts feature men, manhood and/or men nudity). They'd fit, thus, in the official content category, in the sense that they may or may not create narratives and/or a certain narrativity and may or may not be centred on criticism, but they surely focus on reproducing certain contents in the same context as the original production of said contents; in other words, they very simply reproduce languages, discourses, and imagery that is already being produced in the same way and with the same objectives.

Turning our look to a different framework, we have blogs such as You Must Whip $/ t^{12}$, Eroterica ${ }^{13}$, and Dead Girls ${ }^{14}$. In the first one the user(s) appropriate what is commonly called alternative content and amateur videos posted anonymously or not, on Eroterica the appropriation is of that which we've been calling porn industry material (or: professionally made content) and Dead Girls follows the strategy of Double Digit Dongle, conjugating both forms of content.

These differ essentially from the previous three examples mainly because they do use and rely mainly on the category know as hardcore porn (which means full penetration hetero and homossexual sex and explicit intercourse). In comparison, we could argue that the three previous examples fall short of being relevant (though relevance in these matters could be awarded with a paper - and a long one - of its own), especially because, as Bataille puts it (1997, p.118), the expenditure we see in these present examples is "characterized by the fact that in each case the accent is put on the lost that needs to be as big as possible in order for that activity to reach its real meaning".

With this contrast we can affirm that there's a non-socially sanctioned use of violence as a"functional character": it is, "phenomenologically speaking", close to the notion of force or "vigor" - something "singular" and that is a "propriety inherent to an object or person" (Arendt, 2010, p.61-62). The individual, the user, has no access to the circuits of production and neither to the conditions of these productions: he/she does not belong to it, so he forces, through the barrier-free digital environment afforded by the social networking platform Tumblr, a phantasmatic idea (or idealization) of sexuality through expression. Instead of adhering to his/her position as excluded, as mere audience to the feats of sexuality that are staged by actors and distant amateurs, the user/users

\footnotetext{
12 Available at <http://youmustwhipit.tumblr.com/>

13 Available at <http://eroterica.tumblr.com/>

14 Unfortunately this blog has changed its I.P. address and name, making it impossible to supply the reader with the appropriate link to it.
} 
violently transforms these outside manifestations into collages that make sense to them and to others that, equally, also participate doubly in this activity: as other bloggers and as themselves other audiences, and as attested by the footprints, the notes, left behind by each of these blogs and that connect them to other very similar utilize the same strategies, language, and, often, same source material.

"As a rule, a homogeneous society excludes all the heterogeneous elements" (Bataille, 1979, p.74). The dichotomy here becomes evident: we could even argue it's an axiom! As with the non-productive expenditure related to the consumption of cultural products, the strategies of expression perpetrated by the appropriation of said products (be products of the so-called mainstream media or alternative ones) are also affected by this. The heterogeneous exists in and only in relation to the homogeneous, and it needs to know the homogeneous so it can be the other. After all, there can be no I, no self, without an Other, that is also a self.

However, these phenomena go way beyond media content that is well define (as transgressors as they may be) and recognizable and lucrative. Thinking inside the confines of what Kellner (2001) would call media culture per se, we have other examples, such as the blog Anaïs et le Ninja Diaries ${ }^{15}$. Apparently managed by a couple in some sort of long distance romantic and sexual relationship (as per a superficial reading of the text posts, it seems she, Anaïs, lives in Paris, and he, le Ninja, lives somewhere in the north american northwest), they exchange, via mainstream content and reblogs done from amateurish porn producers, erotic and pornographic imagery and texts in a kind of telecourtship or seduction. In Improper $^{16}$ a young woman (she claims to be 21 years old) connects non-conventional sexual pratices (especially eastern and asian ones, such as Japanese bondage techniques, bukkake ${ }^{17}$ and other sadomasochistic practices) with her own dabblings in home-made porn production. Her aim is a sort of narrative that envolves her discoveries of alternate sexual practices and her own attempts at those. She often posts pictures of her own naked body and self inflicted sexual mutilations as well as stories (narrated in the first person,

\footnotetext{
15 Available at $<\underline{\text { http://anaistheninja.tumblr.com/ }>}$

16 Available at $<$ http://improper.tumblr.com/>

17 The practice started in Japan, and consists in men ejaculating at woman's faces. Generally, many men and just one woman and the deflected ejaculation (BATAILLE, 1997, p.118) appears as the only sexual act, without any touching among the participants, and sometimes, the prior act or masturbation doesn't even appears on the scene.
} 
which the authenticity can be questioned) that are either heterosexual or homosexual fantasies.

Another example that would fit this same category is the blog Astronaut Class is a Lie ${ }^{18}$. The user (also a woman, but of indeterminate age) varies between comedic posts (literally posting funny drawings and jokes), posts about imagery from mainstream media culture (usually movies and tv shows), and photos and videos of herself, naked or in revealing wardrobe. She also answers requests made through her Ask Box ${ }^{19}$ : other users ask her to use specific clothes or pose in specific ways and, not rarely, to masturbate or simulate masturbation. She complies with some of the requests and also commercializes videos and photos through other websites - exchanging them for gifts or money.

These examples, however, could never lead us to define this phenomena as sexual expenditure. It is, at most, the leftovers of cultural systems that have been, for the better part of the last four centuries, trying to normalize sexuality and the excess of porn and erotica culture - that constrain participation by physical appearance and/or physical fitness. To better understand that this is, first, not completely unproductive and, secondly, not plainly transgression for the sake of transgression, we need to dabble on other examples, such as the blog Kill Yourself for Recognition ${ }^{20}$ or Slaughter-Faced Jackson ${ }^{21}$.

In the first blog, the user makes satire of famous personalities (such as Hitler, Mussolini, the Pope or even the singer Lady Gaga). In a way, through the collages and altering of famous photos, the user is heterogenizing not only himself, but making clear the force or vigor "that situates these people above men, parties and laws" (Bataille, 1979, p.70). The user chains these satires in a way that a counter-hegemonic narrative emerges from an apparent full-fledged knowledge of the hierarchical order - in other words: the user affirms the powers that be by mocking them. He/she appropriates them, their imagery and discourses, repurposing them into satire or criticism.

The second blog, in a completely different form of chained narrative, appropriates media culture imagery as something that could be defined as horror stories. There's a remix narrative between known icons of capitalist and media culture and extreme violence. In certain posts the user affirms that he

\footnotetext{
18 Available at <http://camdamage.tumblr.com/>

19 Ask Box is a tool that send massages to Tumbler's users even when it doesn't relate to specific posts. It is generally used to express opinions about the content or the person that create or recreate that specific blog.

20 Available at $<\underline{\text { http://death-obsessed.tumblr.com/ }>}$

21 Available at <http://slaughteryourbitch.tumblr.com/>
} 
wants to "rape Ronald McDonald", the mascot of the fast-food chain McDonald's, "with a Nazi flag". Weeks later he posts a constructed image of the scene, using shocking scenes from World War II camps and melted figurines of the toys the fast-food franchise usually sells or gives as gifts to children.

More than those two examples, maybe Tripnamine ${ }^{22}$, a closed-blog (which means only people that know a certain password can access it), could serve us even better to notice and contextualize the excesses that are permissible on Tumblr. In this blog the user builds on this kind of transgressional tradition and composes horrifying images and videos of violence, certainly drawing from closed forums (usually on what is called the Deep Web), with exposed real corpses, footage from car accidents and murder scenes. These accompany all sorts of drug use apology and calls to arms, racial war against the non-pure (which the user does not identify) and rape-related behaviour towards not only women, but children, and the elderly. Mainstream porn and amateurish photos are also comprised in this sort of mosaic of terrors: a not so much chained but almost psychotic narrative emerges from these collages and texts.

The examples found during this brief survey were many. Many more, of course, than we could ever hope to broach in the length of an article or essay. In fact, the complete characterization of any blog mentioned here is problematic at best: they appear and disappear, change handles and usernames, change templates, and, very often, their whole theme. However, as a starting point and the main objective pursued here, we were able to verify some provisional conclusions that could lead to a better understanding of these phenomena. Following Rosenthal (2004, p.50), we realized that "the objective is to reconstruct the social phenomenon in its process of becoming. This applies as much for process of creation and reproduction of established structures as to processes of transformation". In this sense, to approach expenditure in the context of these specific phenomena involves a transformation of Bataille's (1997) category or concept that was originally thought as a critical analytical tool for understanding theatre and literature. This concept must absorb the manifestations provisionally mapped here: they too "provoke fear and horror through the representation of tragic loss (degradation and death)", but, while doing so, they refer to open-ended sexual preferences, practices and the uses of symbolic violence as tools themselves for social upheaval and identity statement. Be that they are sometimes humorous and sometimes shocking, the examples listed here also "provoke laughter through representations that, by

22 Available at <http:/triptamine.tumblr.com/> 
structured comparison, exclude certain seductive elements" (p.120). In other words, whether they shock or entertain (or both), they exclude the exclusion of these Others that they present. They work as affirmations of identifying factors; manifestations of identification.

As a two-stage rocket or a two-stage bomb, the emotional explosions are always accompanied or followed by other related (and sometimes reversed) emotional explosions. The attraction to a certain celebrity or content (be it literary, visual, cinematographic, etc.) comes and happens as a negation of some other content, personality or position, be it diametrically opposite or not. The sexualized versions of this phenomenon repeat this same model: they're accompanied by either love and liberation (even in the form of the abdication of freedom for the freedom of being dominated - a common trope among BDSM practitioners and admirers), either violence or its refusal. Their artistic forms come as emotional and personal manifestation of identities that want to be heard or identities that others want to silence. It is a two-stage bomb, but it is also a paradoxal dichotomy between belonging/homogeneity and wanting to belong/heterogeneity.

This dichotomy is indeed paradoxical - it appears as a continuous and forceful (vigorous, to use Arendt's vocabulary) search and affirmation of a heterogenous identity, but from dozens of blogs analyzed in the course of this brief research only a handful (if not less) produce or made available original or exclusive content (very often because they were in some way or another connected to mainstream content producing centres in media culture or arts). Most of them constructed collages or remixes or even what we came to call chained narratives - with content derived or appropriated from the contemporary mediascape. The narrated identities, as presented through the blogging platform Tumblr, were (re)formulations of mass culture that left behind traces or footsteps leading back to the homogeneous society of which they seem to try to escape. The violence, be it moral, physical, or graphic, of the contents, even those appropriated from a myriad of sources, are still "traces of lives lived" - "marks on a face", as Gadamer would put it (2009, p.174).

The radical lack of control or censorship presented by Tumblr to its users offers a sort of escape to heterogeneity, however, as Bataille would put it, the comprehension of theses processes is necessarily ambiguous and paradoxical: mass media presumes the confrontation between the legitimate, the nonlegitimate and the not-yet-legitimate and appropriations of these contents tend to also appropriate these confrontations. Maybe "the inability of a homogeneous society to find in itself its own reason for being or acting is what 
makes it dependent on imperative forces" (Bataille, 1979, p.74) of heterogeneity that can seem to come from the outside, but are just as dependent from the homogeneous core that they can't find in themselves how to be reinvented.

\section{Bibliography}

ARENDT, Hannah. Sobre a violência. Rio de Janeiro: Civilização Brasileira, 2010. Origens do Totalitarismo. São Paulo: Companhia das Letras, 1989. Sobre a revolução. Lisboa, Portugal: Relógio D'água, 2001.

BATAILLE, Georges. The Bataille Reader. New York, USA:Wiley-Blackwell, 1997.

The Psichological Structure of Fascism. In: New German Critique, N.16, Winter de 1979, p.64-87.

BOYD, D., GOLDER, S. e LOTAN, G. Tweet, Tweet, Retweet: conversational aspectis of retweeting on Twitter. In: HICSS-43. Kauai, HI: IEEEE Press, 2010.

GADAMER, Hans-Georg. Hermenêutica em Retrospectiva. Rio de Janeiro: Vozes, 2009.

HEIDEGGER, Martin. A origem da obra de arte. In: MOOSBURGER, Laura de Borba. "A origem da obra de arte" de Martin Heidegger - Tradução, Comentário e Notas. Dissertação de Mestrado em Filosofia pela Universidade Federal do Paraná, Setor de Ciências Humanas, Letras e Artes, 2007.

KEEN, Andrew. The Cult of the Amateur: How Blogs, MySpace, YouTube, and the rest of today's user-generated media are destroying our economy, our culture, and our values. Doubleday, 2008.

MERLEAU-PONTY, Maurice. Fenomenologia da Percepção. São Paulo: Martins Fontes, 2006.

ROSENTHAL, Gabriele. Biographical Research. In: Qualitative Research Pratice, London: SAGE, 2004.

SFEZ, Lucien. Crítica da comunicação. São Paulo: Edições Loyola, 1994. 
Recebido em: 17/06/2015

Aceito em: 07/10/2015

Endereço do Autor:

Pedro Henrique Baptista Reis <pedro.reis.hb@gmail.com>

Pontifícia Universidade Católica do Rio Grande do Sul (PUCRS)

Av. Ipiranga, 6681

CEP: $90619-900$

Porto Alegre/RS - Brasil 